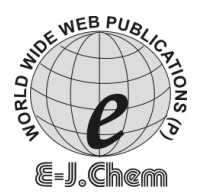

http://www.e-journals.net

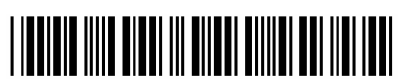

ISSN: 0973-4945; CODEN ECJHAO

E-Journal of Chemistry

Vol. 5, No.3, pp. 567-571, July 2008

\title{
Synthesis of Benzofuro[3,2-e]-1,4-diazepines of Pharmacological Interest
}

\author{
K. M. BASAVARAJA ${ }^{\#}$, V.P.VAIDYA ${ }^{\S *}$ and C.CHANDRASHEKHAR ${ }^{\S}$ \\ \#Department of Industrial Chemistry, Gulberga University, \\ Jnana Ganga, Bellary-Dist: Bellary, Karnataka, India. \\ ${ }^{\S}$ Department of Chemistry, Kuvempu University, Jnana Sahyadri, \\ Shankaraghatta-577451 Dist: Shimoga, Karnataka, India. \\ vaidyavijaya@hotmail.com
}

Received 16 October 2007; Accepted 2 January 2008

\begin{abstract}
The title compounds $(\mathbf{4} \mathbf{a}, \mathbf{b})$ were prepared by chloroacetylation of 2-acyl-3-aminobenzofuran(1a,b) and subsequent treatment with hexamethylene tetramine in ethanol via the complex salts $(\mathbf{3 a}, \mathbf{b})$. Similar reaction with ethyl 3-aminobenzofuran-2 carboxylate (5) produced $3 \mathrm{H}$ benzofuro[3,2-e]-1,4-diazepin2,5(1H,4H)-dione (7) in good yield. All the newly synthesized compounds are characterized by elemental analysis and spectral studies, and evaluated for antimicrobial and anticonvulsant activities.
\end{abstract}

Keywords: Benzofuran, Diazepines, Antimicrobial activity, Anticonvulsant activity

\section{Introduction}

The synthesis of condensed diazepine heterocycles has been explored to a maximum extent owing to their association with wide spectrum of pharmacological activities such as sedatives, anxiolytics, hypnotics, anticonvulsant, antipsychotic, muscle relaxants etc., in recent years ${ }^{1-6}$. Attempts have been made to build 1, 4-diazepine moiety on other biologically potent heterocycles in order to obtain drugs with more efficacy ${ }^{7-11}$. Encouraged by these facts and in continuation of our research program on synthesis of pharmacologically interesting furan derivatives $^{12-16}$, we report in this paper annulation of 1,4-diazepine on benzo[2,1-b]furan moiety and screening the compounds for antimicrobial and anticonvulsant activities. The strategy adopted for the synthesis of these new condensed tricyclic heterocyclic compounds involved successive building up of 1, 4-diazepine ring on benzofuran ${ }^{17}$. 


\section{Experimental}

Melting points were determined in open capillary and are uncorrected. Purity of the compounds was checked by TLC in Silica gel G. PMR spectra were recorded on various A60, FT-80, FT-270 and XL-100 spectrometer using TMS as internal reference. Chemical shifts are expressed in terms of $\delta \mathrm{ppm}$ through out. IR spectra were recorded (nujol) on Perkin-Elmer 277 spectrophotometer. Wave number is expressed in $\mathrm{cm}^{-1}$.

\section{2-Acyl-3-chloroacetamidobenzofurans $(\mathbf{2} \boldsymbol{a}, \boldsymbol{b})$}

A mixture of 2-acyl-3-aminobenzofuran $(0.02 \mathrm{~mol})$ and chloroacetyl chloride $(5 \mathrm{~mL})$ was warmed on water bath for 30 min and poured into ice water with stirring. The solid, which separated, was collected and recrystallized from ethanol as colourless needles.

\section{Hexamethylenetetramine salt of compound $(\mathbf{3 a}, \boldsymbol{b})$}

A mixture of compound 2a, b $(0.002 \mathrm{~mol})$, hexamethylenetetramine $(0.6 \mathrm{~g}, 0.0047 \mathrm{~mol})$ and potassium iodide $(0.2 \mathrm{~g})$ in chloroform $(10 \mathrm{~mL})$ was refluxed on steam bath for $10 \mathrm{~h}$, the residual solid obtained, after removal of solvent, was thoroughly washed with chloroform and then with water to remove excess of HMTA. The product $\mathbf{3 a}, \mathbf{b}$ on recrystallization from ethanol was obtained as colourless needles.

\section{5-Methyl/phenyl-1, 3-dihydro-2H-benzofuran[3,2-e]-1,4-diazepin-2-one(4a,b)}

\section{Method A}

Complex salt 3a, b $(0.00128 \mathrm{~mol})$ was refluxed with ethanol $(10 \mathrm{~mL})$ for $10 \mathrm{~h}$. The excess of solvent was removed under reduced pressure and the residual solid was recrystallised from ethanol yellowish/colourless needles.

\section{Method B}

A mixture of $2 \mathbf{a}, \mathbf{b}$ and hexamethylenetetramine $(0.6 \mathrm{~g}, 0.0047 \mathrm{~mol})$ in ethanol $(10 \mathrm{~mL})$ was heated under reflux for $12 \mathrm{~h}$. the reaction mixture was cooled and the solid separated was filtered and washed with ethanol. The pure compound was obtained by recrystalised with ethanol. The mixed melting points with the compounds obtained by method A were not depressed.

\section{Ethyl 3-chloroacetamido benzofuran-2-carboxylate(6)}

Chloroacetylation of ethyl 3-amino benzofuro-2-carboxylate (5) $(0.025 \mathrm{~g}, 0.01 \mathrm{~mol})$ using chloroacetylchloride $(5 \mathrm{~mL})$ under the reaction conditions described for compounds $3 \mathrm{a}, \mathrm{b}$ gave the title compound as colourless needles when recrystallized in ethanol.

\section{H-Benzofuran[3,2-e]-1,4-diazepine-2,5(1H,4H)-dione (7)}

Through suspension of $\mathbf{6}(0.5 \mathrm{~g}, 0.00178 \mathrm{~mol})$ in absolute methanol $(10 \mathrm{~mL})$, cooled in freezing mixture, dry ammonia gas was passed till saturation. The resulting solution was left room temperature for 4 days. The cloudy solution was concentrated under reduced pressure and then diluted with ether. The solid which separated was filtered and recrystallization from methylene chloride-petroleum ether as colourless granules.

\section{Results and Discussion}

The starting material 2-acyl-3-aminobenzofurans $(\mathbf{1 a}, \mathbf{b})^{18}$ were chloro acetylated to yield compounds 2a,b and were subjected to cyclisation using ammonia. But compound 2a failed to react with ammonia, it did not even produce the expected intermediate 3-aminoacetamido-2-acetylbenzofuran. However, the desired ring closure was accomplished by 
employing hexamethylene tetramine (HMTA). Thus, compound 2a on reaction with HMTA in chloroform produced a complex salt 3a, which on heating with ethanol, underwent cyclization to 5-methyl-1,3-dihydro-2H-benzofuro[3,2-e]-1,4-diazepin-2-one(4a). The direct conversion of 2a to $\mathbf{4 a}$ was also possible by heating 2a with HMTA in ethanol. Similar observations have been made earlier while synthesizing 1, 4-diazepine derivatives ${ }^{19}$. The IR, PMR and mass spectra of $\mathbf{4 a}$ were recorded to substantiate the structure assigned. The IR spectrum showed absorption bands at 1680 and $1625 \mathrm{~cm}^{-1}$ due to $\mathrm{C}=\mathrm{O}$ and $\mathrm{C}=\mathrm{N}$ also a broad band at $3440 \mathrm{~cm}^{-1}$ due NH stretching frequency. The PMR spectrum of $4 \mathbf{a}$ exhibited a singlet at 2.63, integrating for three of $-\mathrm{CH}_{3}$ group, another singlet at 4.26 , integrating for two protons of $-\mathrm{CH}_{2}$ - group, a multiplet at 7.25-8.50 due to four aromatic protons and a broad singlet $\left(\mathrm{D}_{2} \mathrm{O}\right.$ exchangeable $)$ at 11.04 due to $\mathrm{NH}$ proton. It's mass spectrum showed molecular ion peak at $314 \mathrm{~m} / \mathrm{z}$, corresponding to its molecular weight and fragmentation pattern also confirmed the structure assigned.

The additional stimulation for our interest in the 5-phenyl analogue (4b) was due to the fact that phenyl group at position 5 of diazepine moiety enhances the activity ${ }^{20}$. Thus chloroacetylation of 2-benzoyl-3-aminobenzofuran $\mathbf{1 b}$ gave the corresponding chloroacetamide compound $\mathbf{2 b}$ and subsequent treatment of $\mathbf{2 b}$ with HMTA in ethanol gave 5-phenyl-1,3-dihydro-2H-benzofuro[3,2-e]1,4-diazepin-2-one(4b) via the salt $\mathbf{3 b}$ and or directly. Three predominant absorption bands were observed in the IR spectrum of $\mathbf{4 b}$ at 1620,1682 and $3470 \mathrm{~cm}^{-1}$ due to $\mathrm{C}=\mathrm{N}, \mathrm{C}=\mathrm{O}$ and $\mathrm{NH}$ stretching frequencies. The compound 4b exhibited the following PMR data: 4.28(s, 2H, ring $\left.\mathrm{CH}_{2}\right) ; 7.25-8.52(\mathrm{~m}, 9 \mathrm{H}, \mathrm{Ar}-\mathrm{H}) ; 11.54$ $\delta(\mathrm{s}, 1 \mathrm{H}, \mathrm{NH})$, which is in good agreement with the diazepine structure assigned. Another starting material ethyl 3 -aminobenzofuran-2-carboxylate $(\mathbf{5})^{21}$ was also used to build the 1 , 4-diazepine moiety on the similar lines. Thus, treatment of compound $\mathbf{5}$ with chlroacetyl chloride, gave the 3-chloroacetamide compound $\mathbf{6}$, which was subjected to ring closure using methanolic ammonia. Such cyclisations were reported to produce either six memberd pyrimidone or seven memberd 1, 4-diazepine-dione depending on the reaction conditions. ${ }^{22}$ However , under the present experimental conditions $3 H$-benzofuro[3,2-e]-1,4-diazepin2,5(1H,4H)-dione(7), was formed in good yield. The structure of compound 7 is very evident from its IR spectrum which exhibited absorption bonds at 1685 and $3335 \mathrm{~cm}^{-1}$ due to carbonyl and $-\mathrm{NH}$ groups respectively. ${ }^{1} \mathrm{H}$ NMR spectrum of $\mathbf{7}$ is found to be in agreement with the assigned structure (Scheme 1).

The physical data of the newly synthesized compound is presented in Table 1.

Table 1. Characterization data of compounds

\begin{tabular}{|c|c|c|c|c|c|c|c|}
\hline \multirow{2}{*}{$\begin{array}{c}\text { Compd. } \\
\text { No. }\end{array}$} & \multirow{2}{*}{$\mathrm{R}$} & \multirow{2}{*}{$\begin{array}{c}\% \\
\text { Yield } \\
\end{array}$} & \multirow{2}{*}{$\begin{array}{l}\text { M.P } \\
{ }^{0} \mathrm{C} \\
\end{array}$} & \multirow{2}{*}{$\begin{array}{c}\text { Mol. } \\
\text { formula }\end{array}$} & \multicolumn{3}{|c|}{ Found (calculated) } \\
\hline & & & & & $\mathrm{C}$ & $\mathrm{H}$ & $\mathrm{N}$ \\
\hline $2 \mathrm{a}$ & $\mathrm{CH}_{3}$ & 60 & 112 & $\mathrm{C}_{12} \mathrm{H}_{10} \mathrm{NO}_{3} \mathrm{Cl}$ & $57.12(57.25)$ & $3.82(3.98)$ & $5.59(5.57)$ \\
\hline $2 b$ & $\mathrm{C}_{6} \mathrm{H}_{5}$ & 93 & 120 & $\mathrm{C}_{17} \mathrm{H}_{12} \mathrm{NO}_{3} \mathrm{Cl}$ & $65.12(65.07)$ & $3.79(3.83)$ & $4.41(4.47)$ \\
\hline $3 a$ & $\mathrm{CH}_{3}$ & 64 & 174 & ----------- & ------ & ---- & ----- \\
\hline $3 b$ & $\mathrm{C}_{6} \mathrm{H}_{5}$ & 72.13 & 149 & ------------- ～～～ & ----- & ------ & ------- \\
\hline $4 a$ & $\mathrm{CH}_{3}$ & 91.4 & 265 & $\mathrm{C}_{12} \mathrm{H}_{10} \mathrm{~N}_{2} \mathrm{O}_{2}$ & $67.25(67.30)$ & $4.62(4.67)$ & $13.18(13.08)$ \\
\hline $4 \mathrm{~b}$ & $\mathrm{C}_{6} \mathrm{H}_{5}$ & 69 & 265 & $\mathrm{C}_{17} \mathrm{H}_{12} \mathrm{~N}_{2} \mathrm{O}_{2}$ & $73.82(73.91)$ & $4.28(4.35)$ & $10.06(10.15)$ \\
\hline 6 & ---- & 89 & 149 & $\mathrm{C}_{13} \mathrm{H}_{12} \mathrm{NO}_{4} \mathrm{Cl}$ & $55.3(55.42)$ & $4.35(4.46)$ & $5.11(4.97)$ \\
\hline 7 & ----- & 78.2 & 310 & $\mathrm{C}_{11} \mathrm{H}_{8} \mathrm{~N}_{2} \mathrm{O}_{3}$ & $60.92(61.11)$ & $3.65(3.70)$ & $12.89(12.96)$ \\
\hline
\end{tabular}



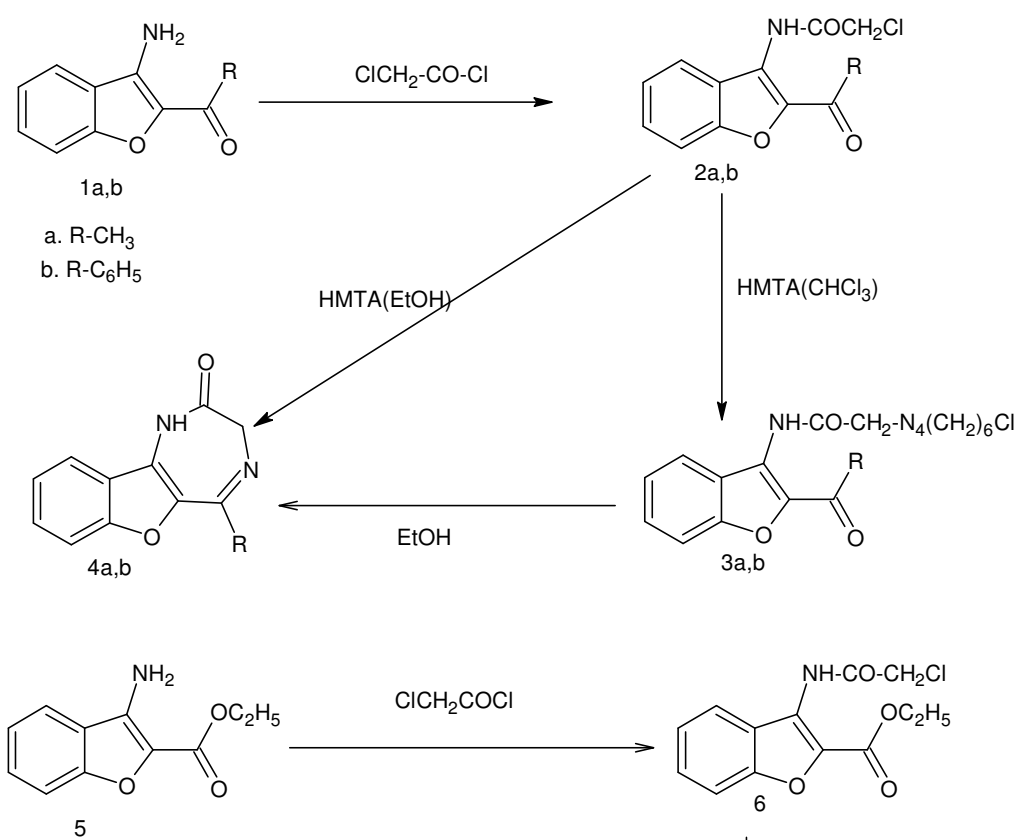

5<smiles>O=C1CNC(=O)c2oc3ccccc3c2N1</smiles>

Scheme 1.

\section{Antimicrobial activity}

The newly synthesized diazepine compounds have been evaluated for antibacterial activity against Staphylococcus aureus and Klebsiella pneumoniae and antifungal activity against Aspergillus niger and Candida albicans by using ciprofloxacin and ciclopirox olamine as standards for comparison for antibacterial and antifungal activity respectively, by cup-plate method $^{23}$. The results indicate that the compounds were either weakly active or inactive against all the four microorganisms.

\section{Anti convulsant activity}

The compounds were screened for anticonvulsant activity by maximal electroshock (MES) induced convulsant method ${ }^{24}$ on albino rats (Wistar strain) using diazepam at the dose of $25 \mathrm{mg} / \mathrm{kg}$ body weight, as standard. After carrying out dose fixation studies, by stair-case method, the compounds were at the dose of $80 \mathrm{mg} / \mathrm{kg}$ body weight. A current of 150 ma was applied to the rats for 0.2 seconds, through corneal electrodes and the time 
spent by the rats in different stages of convulsions were noted. The diazepine $\mathbf{4 b}$ was found to possess considerable anticonvulsant activity, since it reduced the extensor phase of the MES convulsions to a greater extent than $\mathbf{4 a}$ and comparable with that of standard drug. Electron with drawing phenyl group present on diazepine ring may be responsible for its enhanced activity as compared with $4 \mathrm{a}$ which contains electron donating group in the same position.

\section{References}

1. Childress S J and Gluckmen M I, J. Pharm. Sci., 1964, 53, 577.

2. Dechereq, E. Med. Rev., 1993, 13, 229.

3. Liu L and Dodd R H, J. Heterocyclic Chem., 1995, 32, 523.

4. Hiremath S P, Goudar N N and Purohit M G, Ind. J. Chem., 1980, 19B, 848.

5. Zellou A, Charrah Y, Essassi E M, and Hassar M, Ann. Pharm. Fr., 1998, 56, 175.

6. Michelini S, Cassano G B, Frare F and Perugi G, Pharmacopeychiatry, 1996, 29, 127.

7. Zang P, Zang N, Buckwold V E and Hosamane R S , Biorg. and Med. Chem., 2007, 15(14), 4933.

8. Movikov M S, Amer A A and Khlebnikev A F, Tetrahedron let., 2006, 47(5), 639.

9. $\quad$ Braun R V and Muller T J J, Tetrahedron, 2004, 60(42), 9463.

10. Roma G, Grossi G C, Braccio M D, Ghia M and Mattioli F, Euro. J. Med. Chem. 1991, 26(5), 489.

11. Hosamane R S, Vaidya V P and Mi kyung Chung, Nucleosides and Nucleoside, 1991, 10(8), 1693.

12. Ravindra K C, Vaidya V P, Chandrashekhar C and Vagdavi H M, Ind. J. Hetrocyclic Chem., 2006, 15, 283.

13. Vaidya V P, Vagdevi H M, Mahadevan K M and Shreedhara C S , Ind. J. Chem., 2004, 43B 153.

14. Vagdevi H M, Latha K P, Vaidya V P, VIjayakumar M L and Pai K S R, Ind. J. Pharm. Sci., 2001, 63(4), 1286.

15. Mahadevan K M, Basavaraj K M, Prathima Mathias D A and Vaidya V P, Ind. J. Chem 2005, 44B, 789.

16. Mahadevan K M, Vaidya V P, and Vagdevi H M, Ind J Chem, 2003, 42(B), 1931.

17. Archor G A and Sternbach L H, Chem. Rev. 1968, 747.

18. Vaidya V P, Mahajan S B and Agasimundin Y S, Ind. J. Chem. 1981, 20B, 391.

19. Blazevic N and Kajfez F, J. Hetrocycl. Chem., 1970, 7, 1173.

20. Granik V G, Zhidkova A M, Anisimova O S and Gulshkov P G, Khim. Geterotsikl. Soedin, 1975, 716.

21. Harwalker G S and Agasimundin Y S, Ind. J. Heterocyclic Chem., 1994, 3, 247.

22. Uskokovic M, Iacobelli J, Toome V and Wenner W, J. Org. Chem., 1964, 27, 3606.

23. Giand K N, Dar R n, Chopra B M and Kaul R N, Ind. J. Pharm. Sci., 1965, 27, 141.

24. Rubat C, Coudert P, Coupuelet J M, Thvonche P, Bastide J and Bastide P, Farmaco, 1990, 45(3), 331. 


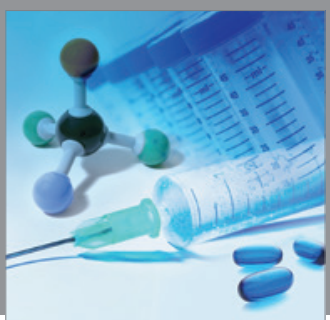

International Journal of

Medicinal Chemistry

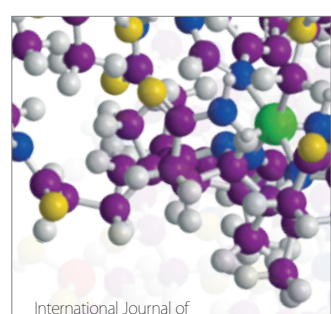

Carbohydrate Chemistry

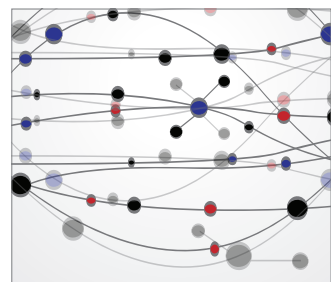

The Scientific World Journal
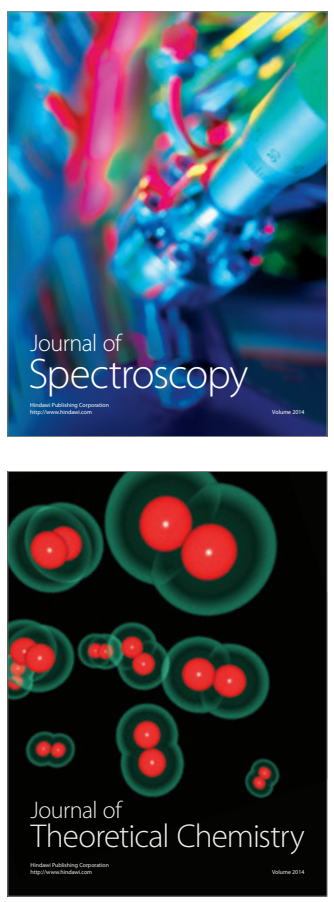
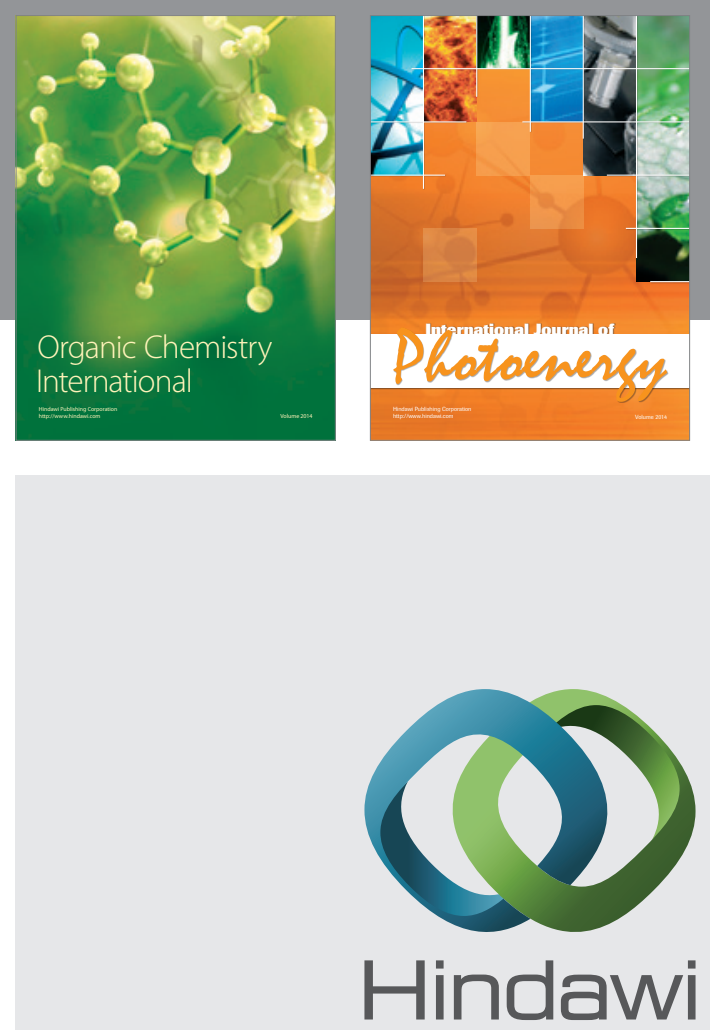

Submit your manuscripts at

http://www.hindawi.com
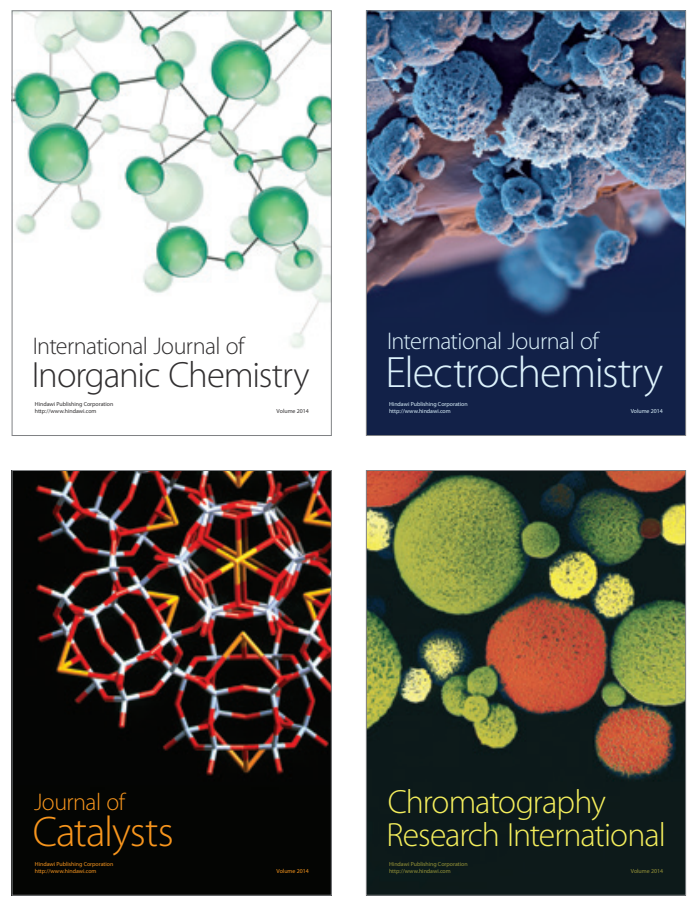
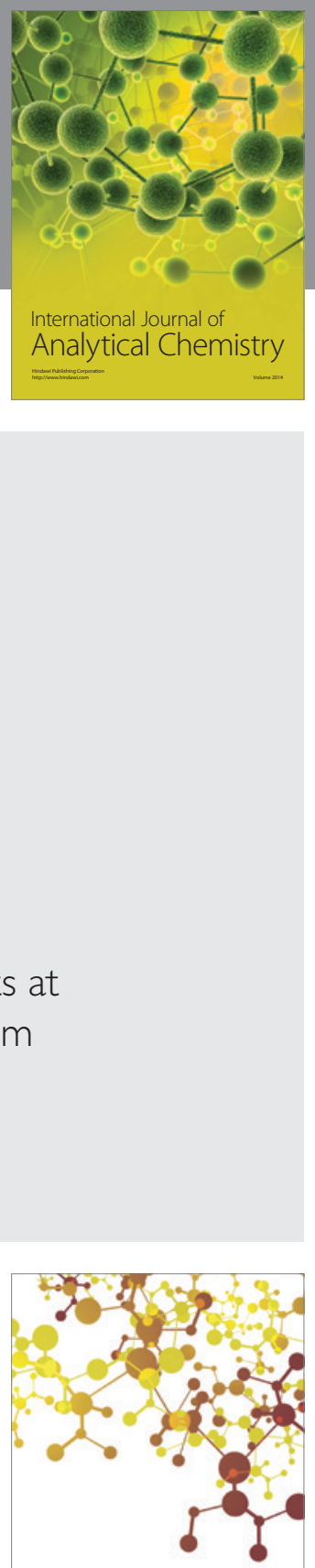

Journal of

Applied Chemistry
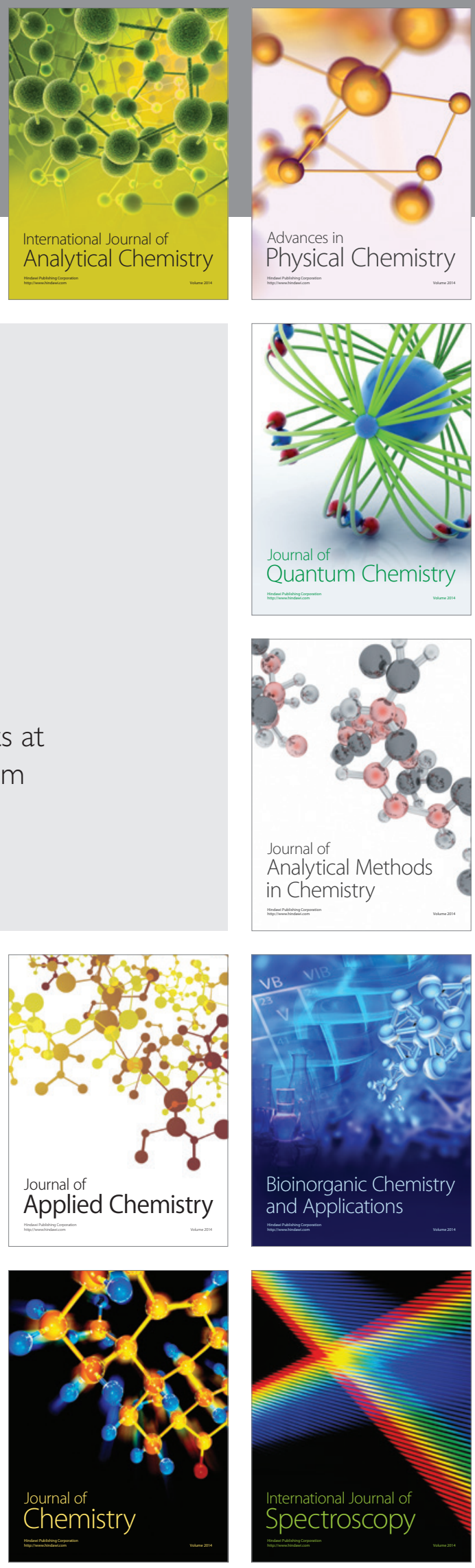